DOI: 10.20472/IAC.2017.33.025

YURIKO ISADA

Kwansei Gakuin University, Japan

\title{
AN EMPIRICAL STUDY ABOUT A BYSTANDER'S BEHAVIOUR AND PSYCHOLOGICAL STATE IN BULLYING
}

\begin{abstract}
:
The objective of this research is to clarify empirically about the relationship of a bystander's behaviour of bullying and psychological state of bystanders. To decrease bystander of bullying is effective to resolve bullying. However, the number of bystanders indicate a tendency to increase in Japan. The percentage of bullies who were reported by their classmates was $10 \%$ until 2010 . It decreased to around 3\% recently. In this research, the hypothesis that low consciousness of others raise the number of bystanders was formed. As a methodology, the questionnaire to 300 ordinary citizens was carried out.

As a result of the survey, especially multidimensional sympathies, consciousness of others, and Japanese version of the Buss-Perry Aggression Questionnaire correlated to a bystander's behaviour of bullying. In conclusion, the effort towards to raise consciousness of others is useful to decrease a number of bystanders.
\end{abstract}

\section{Keywords:}

Bullying, bystander's behaviour, psychological state, questionnaire

JEL Classification: Z13, H00, I29 